\title{
Rapid and Sensitive Determination Of Montelukast in Human Plasma by High Performance Liquid Chromatographic Method Using Monolithic Column: Application to Pharmacokinetic Studies
}

Alireza Shafaati ${ }^{1 *}$, Afshin Zarghi', Seyed Mohsen Foroutan ${ }^{1}$, Arash Khoddam ${ }^{2}$ and Babak Madadian ${ }^{2}$

${ }^{1}$ School of Pharmacy, Shaheed Beheshti University of Medical Sciences, Tehran, P.O.Box: 14155-6153, Iran

${ }^{2}$ Noor Research and Educational Institute, Tehran, Iran

\begin{abstract}
A rapid, simple and sensitive high-performance liquid chromatography (HPLC) method, using a monolithic column and fluorescence detection, has been developed for quantification of montelukast in human plasma. Ethoxyquine, easily available as a pharmaceutical substance, was selected as internal satandard. The assay enables the measurement of montelukast for therapeutic drug monitoring with a minimum detectable limit of $5 \mathrm{ng} / \mathrm{ml}-1$. The method involves simple, one-step extraction procedure and analytical recovery was about $97 \%$. The separation was carried out in reversedphase conditions using a Chromolith RP $\circledast(R P-18 \mathrm{e}, 100 \mathrm{~mm} \times 4.6 \mathrm{~mm})$ column at ambient temperature. The mobile phase was $56 \%$ acetonitrile and $50 \mathrm{mM}$ sodium dihydrogen phosphate, and distilled water to $100 \%$, adjusted to $\mathrm{pH} 7.0$ at a flow rate of $2 \mathrm{ml} / \mathrm{min}$. The excitation wavelength was set at $350 \mathrm{~nm}$, emission at $450 \mathrm{~nm}$. The calibration curve was linear over the concentration range $20-800 \mathrm{ng} / \mathrm{ml}$. The coefficients of variation for inter-day and intra-day assay were found to be less than $7 \%$. The method was applied to the determination of montelukast in plasma from 12 subjects dosed with montelukast $10 \mathrm{mg}$ tablets and pharmacokinetic parameters were determined.
\end{abstract}

Keywords: Montelukast; Determination; Human Plasma; HPLC; Monolithic Column

\section{Introduction}

Montelukast sodium [1] is described chemically as [R-(E)]-1[[[1-[3-[2-(7-chloro-2quinolinyl) ethenyl]phenyl]-3-[2-(1-hydroxy1-methylethyl)phenyl]propyl]thio] methyl] cyclopropane acetic acid, monosodium salt (Figure 1). Montelukast is a selective and orally active leukotriene receptor antagonist that inhibits the cysteinyl leukotriene $\mathrm{CysLT}_{1}$ receptor $[2,3]$. The drug is indicated for the prophylaxis and chronic treatment of asthma in adults and pediatric patients 12 months of age and older. It is also indicated for prevention of exerciseinduced bronchoconstriction in patients 15 years of age and older and for the relief of symptoms of seasonal allergic rhinitis in adults and pediatric patients 2 years of age and older [2-4]. Montelukast is rapidly absorbed following oral administration and is extensively metabolized. Montelukast and its metabolites are excreted almost exclusively via the bile [5]. In several studies, the mean plasma half-life of montelukast ranged from 2.7 to 5.5 hours in healthy young adults $[5,6]$. The pharmacokinetics of montelukast is nearly linear for oral doses up to $50 \mathrm{mg}[6]$.

In order to study the pharmacokinetics of montelukast in humans, a sensitive and reliable assay of the drug in biological fluids is necessary. Various analytical methods have been reported for the determination of montelukast in bulk or pharmaceutical dosage forms [7-10] and in biological fluids [1,10-13]. Recently, [14] published an excellent paper on development and validation of a bioanalytical method for determination of montelukast in human plasma using HPLC. In their paper, they also reviewed and compared the published HPLC methods for determination of montelukast in human plasma. Compared to other reports, the method reported by Sripalakit and colleagues was simple and the total run time (i.e. 9 minutes) was less than the time previously reported for similar methods. Furthermore, they used mefenamic acid as internal standard, which is available commercially. In our study, we have developed and validated a very simple method based on using a monolithic column, by which the consumption of acetonitrile in the mobile phase has been reduced from $70 \%$ to $56 \%$. Moreover, although we have achieved a base line resolution between the internal standard and the major peak, the lag time between the two peaks (which is more than 4 minutes in Sripalakit's paper) has been reduced to less than 2 minutes. This in turn, led to a shortened analysis time $(<5 \mathrm{~min}$.) and further reduction in the acetonitrile consumption. Thus, the present<smiles>CC(C)(O)c1ccccc1CC[C@H](SCC1(CC(=O)O)CC1)c1cccc(/C=C/c2ccc3ccc(Cl)cc3n2)c1</smiles><smiles>CCOc1ccc2c(c1)C(C)=CC(C)(C)N2</smiles>

Ethoxyquin

Figure 1: Chemical structure of montelukast (MO) and ethoxyquine (internal standard, I.S.)

*Corresponding author: Alireza Shafaati, Professsor of pharmaceutica chemistry, School of Pharmacy, Shaheed beheshti University of Medical Sciences Tehran, P.O.Box: 14155-6153, Iran, E-mail: ashafaati@yahoo.com

Received May 24, 2010; Accepted November 22, 2010; Published December 30,2010

Citation: Shafaati A, Zarghi A, Foroutan SM, Khoddam A, Madadian B (2010) Rapid and Sensitive Determination Of Montelukast in Human Plasma by High Performance Liquid Chromatographic Method Using Monolithic Column: Application to Pharmacokinetic Studies. J Bioequiv Availab 2: 135-138. doi:10.4172/ jbb.1000046

Copyright: (c) 2010 Shafaati A, et al. This is an open-access article distributed under the terms of the Creative Commons Attribution License, which permits unrestricted use, distribution, and reproduction in any medium, provided the original author and source are credited. 
method is less hazardous to human health and to the environment as well as being faster and more economic.

\section{Materials and Methods \\ Chemicals and reagents}

Montelukast sodium and ethoxiquine standard powders were kindly gifted by Sobhan Daru Pharmaceutical Company (Tehran, Iran). HPLC grade acetonitrile, analytical grade disodium hydrogen phosphate, phosphoric acid, and all other chemicals were purchased from Merck (Darmstadt, Germany). High purity water was supplied by Milli-Q Water Purification System (Millipore, Billerica, MA).Human plasma was supplied by Noor Educational and Research Institute (Tehran, Iran).

\section{Chromatographic conditions}

The HPLC system (Knauer, Germany) consisted of a K1001 pump and a RX-10AXL spectrofluorometric detector and controlled by Eurochrom 2000 (Integration Package) software. The analytical column employed was Chromolith $\mathrm{RP}^{\infty}(100 \mathrm{~mm} \times 4.6 \mathrm{~mm}$ i.d. $)$ purchased from Merck (Germany). The mobile phase was comprised of acetonitrle-50 $\mathrm{mM}$ phosphate buffer $\mathrm{pH} 7.0$ (56\% - 46\% v/v, respectively). The mobile phase was prepared freshly and was filtered before use. All separations were performed isocratically at a flow rate of $2.0 \mathrm{ml} / \mathrm{min}$ and column condition was maintained at ambient temperature. The detector was operated at an excitation wavelength of $350 \mathrm{~nm}$ and an emission wavelength of $450 \mathrm{~nm}$.

\section{Standard solutions}

Blank plasma was prepared from heparinized whole-blood samples collected from healthy volunteers and stored at $-20^{\circ} \mathrm{C}$. Stock solution of montelukast sodium was prepared with concentration of $0.01 \mathrm{mg} / \mathrm{ml}$ in water and diluted with drug free human plasma or the mobile phase to the desired concentration. Due to the sensitivity of montelukast to the light [8,9], exposure of the drug solution to the light was carefully avoided. Ethoxyquine was dissolved in acetonitrile at a concentration of $0.4 \mathrm{mg} / \mathrm{ml}$. A series of plasma standard solutions of montelukast sodium were prepared with concentrations of 20, 200, 350, 500, 650 and $800 \mathrm{ng} /$ $\mathrm{ml}$, and each one containing the internal standard at a concentration of $40 \mathrm{ng} / \mathrm{ml}$. Also, quality control standard solutions were prepared containing low $(100 \mathrm{ng} / \mathrm{ml})$, median $(300 \mathrm{ng} / \mathrm{ml})$ and high $(600 \mathrm{ng} / \mathrm{ml})$ concentrations of the drug in plasma to assess accuracy of the method and intra- and inter-day variations. All solutions of montelukast were kept at $4^{\circ} \mathrm{C}$ and all plasma solutions of the drug were stored at $-20^{\circ} \mathrm{C}$ until analysis.

\section{Biological samples}

Montelukast was administered in a single dose of $10 \mathrm{mg}$ to twelve healthy volunteers after overnight fasting. Blood samples (3-4 ml) were collected at several intervals after dosing and transfered into heparinized tubes. After centrifugation at $5000 \mathrm{rpm}$ for $10 \mathrm{~min}$, resultant plasma was separated and frozen immediately at $-20^{\circ} \mathrm{C}$ until assayed.

\section{Sample preparation}

All plasma samples were thawed at room temperature immediately before assayed. To a $500 \mu \mathrm{l}$ of plasma sample in a glass-stoppered 15 $\mathrm{ml}$ centrifuge tube $50 \mu \mathrm{l}$ of the internal satndard solution $(600 \mathrm{ng} / \mathrm{ml})$ and $200 \mu \mathrm{l}$ saturated solution of $\mathrm{NaCl}$ were added [15]. The mixture was mixed (30 s) and was centrifuged for $10 \mathrm{~min}$ at $8000 \mathrm{rpm}$. Then, $20 \mu \mathrm{l}$ of the supernatant was injected into liquid chromatography.

\section{Stability}

The stability of montelukast was assessed during all steps of the method including storage and analysis. No changes in stability over the period of one month were observed (provided that all samples and solutions are kept in amber glass containers or protected from light by wrapping containers and tubes in aluminum foil).

\section{Selectivity and specificity}

Control human plasma, obtained from 12 healthy volunteers, was assessed by the procedure as described above and compared with respective plasma samples to evaluate selectivity of the method.

\section{Precision and accuracy}

The precision and accuracy of the method were examined by adding known amounts of montelukast (20,300 and $600 \mathrm{ng} / \mathrm{ml}$ to pool plasma (quality control samples). For intra-day precision and accuracy five replicate quality control samples at each concentration were assayed on the same day. The inter-day precision and accuracy were evaluated on three different days.

\section{Limit of quantification (LOQ) and recovery}

For the concentration to be accepted as LOQ, the percent deviation from the nominal concentration (accuracy) and the relative standard deviation must be $\pm 10 \%$ and less than $10 \%$, respectively, considering at least five times the response compared to the blank response [15]. The relative analytical recovery for plasma at three different concentrations of montelukast $(100,300$ and $600 \mathrm{ng} / \mathrm{ml})$ was determined. Average recovery of montelukast was determined by comparing AUC obtained after injection of the processed QC samples with those achieved by direct injection of the same amount drug in distilled water at different concentrations (six samples for each concentration level).

\section{Plasma calibration curves and quantitation}

After thawing, a series of plasma standard solutions of montelukast sodium were prepared with concentrations of 20, 200, 350, 500, 650 and $800 \mathrm{ng} / \mathrm{ml}$, each one containing the internal standard at a concentration of $40 \mathrm{ng} / \mathrm{ml}$.The samples were then prepared for analysis as described above. Calibration curves were constructed by plotting peak area ratio (y) of montelukst to the internal standard versus the drug concentration (x). A linear regression was used for quantitation.

\section{Pharmacokinetic design and analysis}

The proposed method was applied to evaluate the pharmacokinetic of montelukast in 12 healthy male volunteers with a mean age of $25.9 \pm$ 4.2 years and body mean weight of $72 / 7 \pm 2.5 \mathrm{~kg}$. Each volunteer was orally administered 10mg montelukast (Sobhan Daru Pharmaceutical Company, Tehran, Iran) under fasting conditions. Blood samples were collected in heparinized tubes before and at $0.5,1,1.5,2,2.5$, $3,3.5,4,5,7,10$ and $24 \mathrm{~h}$ after dosing and centrifuged to obtain the plasma fraction. The plasma samples were kept in cryogenic vial stored at $-20^{\circ} \mathrm{C}$ until analysis. Montelukast pharmacokinetic parameters were determined by non-compartmental methods. Elimination rate constant $(K)$ were estimated by the least-square regression of plasma concentration-time data points lying in the terminal log-linear region of the curves. Half-life $\left(\mathrm{T}_{1 / 2}\right)$ was calculated as 0.693 divided by $\mathrm{K}$. The area under the plasma concentration-time curve from time zero to the last measurable concentration at time $\mathrm{t}\left(\mathrm{AUC}_{0-\mathrm{t}}\right)$ was calculated using the trapezoidal rule (Foroutan et al, 2003). The area was extrapolated to infinity $\left(\mathrm{AUC}_{0-\infty}\right)$ by addition of $\mathrm{C}_{\mathrm{t}} / K$ to $\mathrm{AUC}_{0-\mathrm{t}}$ where $\mathrm{C}_{\mathrm{t}}$ is the last detectable drug concentration. Peak plasma concentration $\left(\mathrm{C}_{\max }\right)$ and time to peak concentration $\left(\mathrm{T}_{\max }\right)$ were derived from the individual subject concentration time curves. 
Citation: Shafaati A, Zarghi A, Foroutan SM, Khoddam A, Madadian B (2010) Rapid and Sensitive Determination Of Montelukast in Human Plasma by High Performance Liquid Chromatographic Method Using Monolithic Column: Application to Pharmacokinetic Studies. J Bioequiv Availab 2: 135-138. doi:10.4172/jbb.1000046

\section{Results}

\section{Chromatography separation}

Under the chromatographic conditions described, montelukast and the internal standard peaks were well resolved. No interfering peaks from endogenous plasma components were observed. Typical chromatograms of blank plasma in comparison to spiked samples analyzed for pharmacokinetics study are shown in Figure 2. The monolithic column has lower flow impedance comparing to the particulate packings, and therefore allows applying higher flow rate and easy optimization of chromatographic conditions [16] to obtain desirable resolution in a short time $(<5 \mathrm{~min})$. A mobile phase consisted of acetonitrile and phosphate buffer in the ratio of 56: $44 \% \mathrm{v} / \mathrm{v}$, respectively, was optimum to achieve the best resolution between montelukast and the internal standard. The average retention times of the internal standard 1 and montelukast were 2.3 and 3.7 min, respectively. Ethoxyquine, easily available as a pharmaceutical substance, was selected among many compounds we tested as internal satandard because of its structural similarity to montelukast and appropriate chromatographic behavior.

\section{Method validation}

As shown in Table 1, the calibration curve for the determination
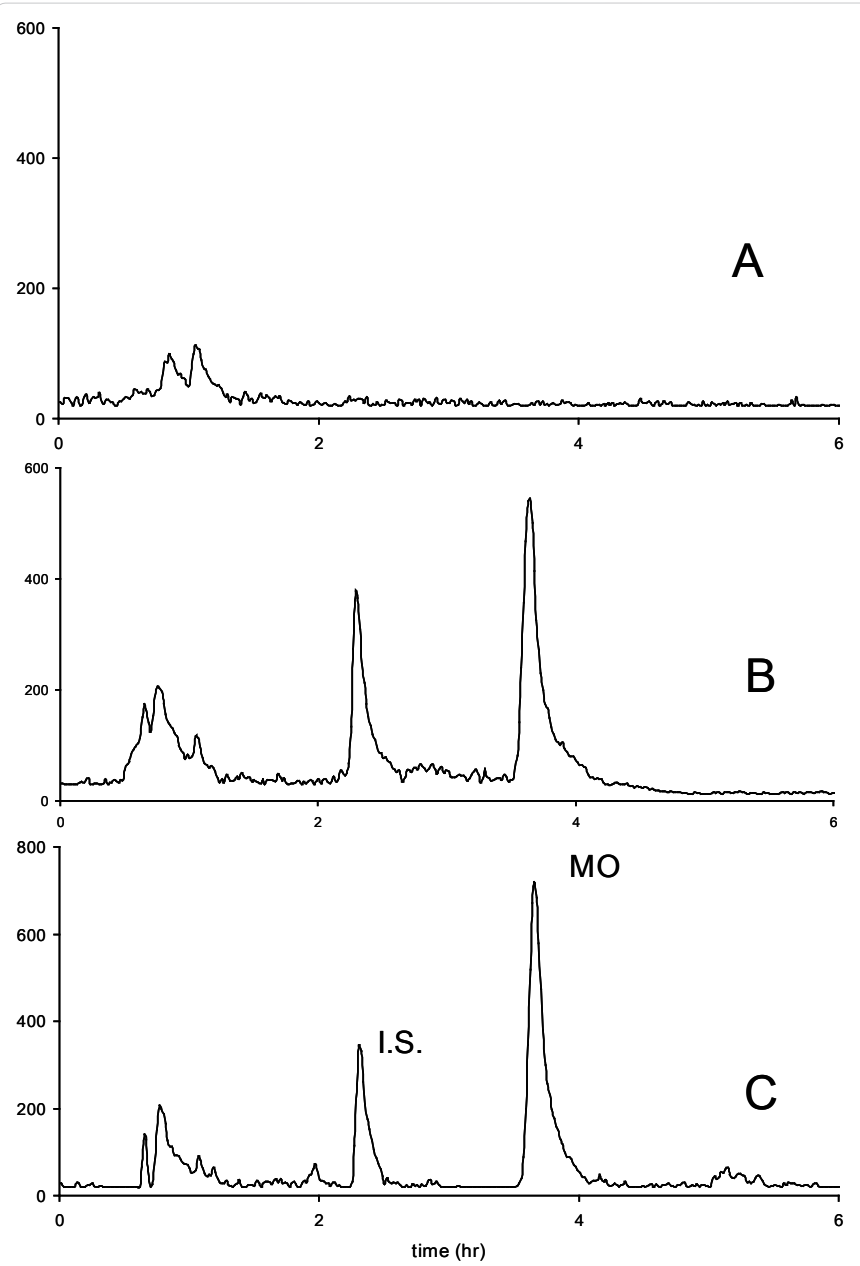

Figure 2: Chromatograms of $(A)$ blank plasma; (B) blank plasma spiked with $300 \mathrm{ng} / \mathrm{ml}$ montelukast and $40 \mathrm{ng} / \mathrm{ml}$ ethoxyquine (internal standard); (C) plasma sample from a healthy volunteer $1.5 \mathrm{~h}$ after oral administration of 10 mg montelukast.

\begin{tabular}{|c|c|c|c|}
\hline \multicolumn{2}{|c|}{$\begin{array}{l}\text { Coefficient of the linear regression } \\
\text { analysis }(r \pm S D)\end{array}$} & \multirow{2}{*}{$\begin{array}{l}\text { Slope } \pm \text { SD } \\
0.00723 .0 \quad 10^{-5}\end{array}$} & \multirow{2}{*}{$\begin{array}{l}\text { Intercept } \pm \text { SD } \\
0.01822 .010^{-4}\end{array}$} \\
\hline Intra-assay & $0.9993 \pm 6.3 \times 10^{-4}$ & & \\
\hline$n=6$ & $\mathrm{RSD}=0.063 \%$ & $\mathrm{RSD}=0.42 \%$ & \\
\hline Inter-assay & $0.9995 \pm 7.2 \times 10^{-4}$ & $0.00655 .0 \quad 10^{-5}$ & $0.01623 .010^{-4}$ \\
\hline$n=9$ & $\mathrm{RSD}=0.072 \times 10^{-4}$ & $\mathrm{RSD}=0.77 \%$ & \\
\hline
\end{tabular}

\begin{tabular}{|l|l|l|}
\hline $\begin{array}{l}\text { Concentration added } \\
\text { (ng/ml) }\end{array}$ & \multicolumn{2}{|c|}{ Peak area ratio (mean \pm SD) } \\
\hline 20 & Intra-day & Inter-day \\
\hline 300 & $0.21 \pm 0.01(4.8)$ & $0.22 \pm 0.01(4.5)$ \\
\hline 600 & $2.16 \pm 0.13(6.1)$ & $2.03 \pm 0.05(2.6)$ \\
\hline & $3.61 \pm 0.17(4)$. & $3.51 \pm 0.16(4.6)$ \\
\hline
\end{tabular}

Values in parentheses are relative standard deviations (\%)

Table 2: Reproducibility of the analysis of montelukast in human plasma $(n=5)$.

\begin{tabular}{|l|l|}
\hline Parameter & Result \\
\hline$C_{\max }(\mathrm{ng} / \mathrm{ml})$ & $499.34 \pm 133.69$ \\
\hline $\operatorname{Tmax}(\mathrm{h})$ & $2.42 \pm 0.19$ \\
\hline$A \cup C_{(0-t)}$ & $2315.30 \pm 712.20$ \\
\hline$A \cup C_{(0-\infty)}$ & $3044.96 \pm 990.13$ \\
\hline$T_{1 / 2}(h)$ & $4.40 \pm 0.99$ \\
\hline el $\left(\mathrm{h}^{-1}\right)$ & $0.17 \pm 0.04$ \\
\hline
\end{tabular}

Table 3: Mean pharmacokinetic parameters ( \pm SD) of montelukast following administration of $10 \mathrm{mg}$ the drug $(n=12)$.

of montelukast in plasma was linear over the range $20-800 \mathrm{ng} / \mathrm{ml}$. The linearity of this method was statistically confirmed. For each calibration curve, the intercept was not statistically different from zero. The correlation coefficients $(r)$ for calibration curves were equal to or better than 0.999 . The relative standard deviation (RSD) values of the slope were less than $2 \%$. For each point of calibration standards, the concentrations were recalculated from the equation of the linear regression. The analytical recovery for plasma at three different concentrations of montelukast was determined. Known amounts of the drug were added to drug-free plasma in concentrations ranging from $20-600 \mathrm{ng} / \mathrm{ml}$. The internal standard was added and the absolute recovery of montelukast was calculated by comparing the peak areas for extracted montelukast from spiked plasma and a standard solution of montelukast in acetonitrile containing internal standard with the same initial concentration. The average recovery was $98.2 \pm 1.5 \%$. Using fluorescence detection, the limit of quantification (LOQ), as previously defined, was $5 \mathrm{ng} / \mathrm{ml}$ for montelukast. This is sensitive enough for drug monitoring and for pharmacokinetic studies.

We assessed precision of the method by repeated analysis of plasma specimens containing known concentrations of montelukast. As shown in Table 2, coefficients of variation were less than $7 \%$, which is acceptable for the routine measurement of the drug. Stability was determined for spiked plasma samples under the conditions as described above. The results showed that the samples were stable under the conditions used for storage.

\section{Application to pharmacokinetic study}

In this study plasma concentrations were determined in twelve healthy volunteers, who received a single oral dosing of 10-mg tablet formulation. The derived pharmacokinetic parameters of 12 healthy volunteers are summarized in Table 3 . The mean plasma concentrationtime curve of montelukast is shown in Figure 3. The plasma concentration of montelukast reached to a maximum $2.42 \pm 0.19 \mathrm{~h}$ after dosing with a level of $499.34 \pm 133.69 \mathrm{ng} / \mathrm{ml}$. These pharmacokinetic parameters are in good agreement with those found previously and no 


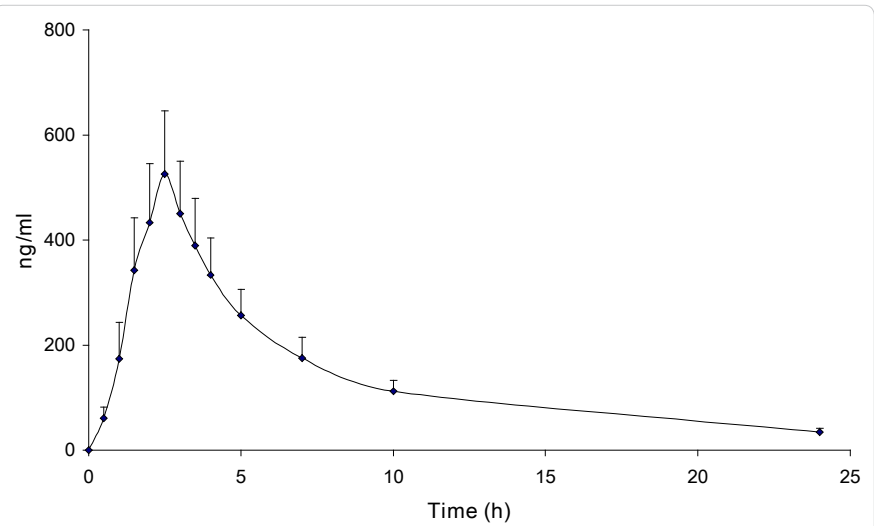

Figure 3: Mean plasma concentration-time profile of montelukast in healthy volunteers $(n=12)$ after a single dose of $10 \mathrm{mg}$ montelukast.

significant difference was observed between our pharmacokinetic data and results reported in the literature $[5,6]$.

\section{Discussion}

The aim of our study was to develop a rapid and sensitive method for the routine analysis of biological samples in pharmacokinetic montelukast research. This method is well suited for routine application in the clinical laboratory because of the speed of analysis and simple extraction procedure. Over 300 plasma samples were analyzed by this method without any significant loss of resolution. No change in the column efficiency or increase in backpressure was observed over the entire study time, thus proving its suitability.

In the present method we used a protein precipitation extraction, HPLC on a monolithic column and fluorescence detection to give high sensitivity [16]. The published HPLC methods for determination of montelukast in human plasma were summarized in an excellent paper published by [14]. They presented in their paper, a simple bioanalytical assay for determination of montelukast in human plasma and its application to a pharmacokinetic study and compared to the previously reported methods. Then, they concluded that their method is advantageous over most of the reported methods because of the shorter analysis time and availability of the internal standard. In our method, in this work, total analysis time is even shorter and separation achieved in less than 5 minutes. Moreover, separation was performed on a monolithic column which resulted in lower consumption of the acetonitrile as an organic modifier in the mobile phase. Further reduction in the acetonitrile consumption was resulted due the shorter total analysis time. Therefore, the present method is less hazardous to human health and to the environment as well as being faster and more economic. These results were obtained along with the same sensitivity and selectivity as described by [14].

The present method proved to be reproducible and reliable based on the results of validation assessment. Also, sensitivity and selectivity of the method allowed us to apply it successfully for the routine analysis of biological samples in pharmacokinetic research on montelukast.

\section{Conclusions}

We developed a rapid, simple, accurate and reproducible method for determination of montelukast in plasma. The proposed method is less hazardous to human health and to the environment as well as being faster and more economic. This method will permit pharmacokinetic and pharmacodynamic studies of the drug in humans.

\section{Acknowledgements}

This work was supported by Noor Research and Educational Institute.

\section{References}

1. Schoors DF, Smet MD, Reiss T, Margolskee D, Cheng H, et al. (1995) Single dose pharmacokinetics, safety and tolerability of MK-0476, a new leukotriene D4-receptor antagonist, in healthy volunteers. Br J Clin Pharmacol 40: 277-280.

2. Emuzyte R, Firantiene R, Petraityte R, Sasnauskas K (2009) Human rhinoviruses, allergy, and asthma: a clinical approach. Medicina (Kaunas) 45 839-847.

3. Peters-Golden M, Gleason MM, Togias A (2006) Cysteinyl leukotrienes: mulitfunctional mediators in allergic rhinitis. Clin Exp Allergy 36: 689-703.

4. Hay DW (1997) Pharmacology of leukotriene receptor antagonists. More than inhibitors of bronchoconstriction. Chest 111: 35S-45S.

5. Merck \& Co WS NJ (2010) Singulair (montelukast sodium). Product information (Cited 2010 April 20)

6. Kearns GL, Lu S, Maganti L, Li XS, Migoya E, et al. (2008) Pharmacokinetics and safety of montelukast oral granules in children 1 to 3 months of age with bronchiolitis. J Clin Pharmacol 48:502-511.

7. Hoang TH, Farkas R, Wells C, McCliutock A, Maso MD (2002) Application of pressurized liquid extraction technology to pharmaceutical solid dosage forms. J Chromatogr A 968: 257-261.

8. Radhakrishna T, Narasaraju A, Ramakrishna M, Satyanarayana A (2003) Simultaneous determination of montelukast and loratadine by HPLC and derivative spectrophotometric methods. J Pharm Biomed Anal 31: 359-368.

9. Ibrahim A. Alsarra (2004) Development of a stability-indicating hplc method for the determination of montelukast in tablets and human plasma and its applications to pharmacokinetic and stability studies. Saudi Pharm. J 12: 136143

10. Shakalisava Y, Regan F (2008) Determination of montelukast sodium by capillary Electrophoresis. J Sep Sci 31: 1137-1143

11. Liu L, Cheng H, Zhao JJ, Rogers JD (1997) Determination of montelukast (MK-0476) and its S-enantiomer in human plasma by stereoselective highperformance liquid chromatography with column-switching. J Pharm Biomed Anal 15: 631-638.

12. Ochiai H, Uchiyama N, Takano T, Hara K, Kamei T (1998) Determination of montelukast sodium in human plasma by column-switching high performance liquid chromatography with fluorescence detection. J Chromatogr B Biomed Sci Appl 713: 409-414.

13. Kitchen CJ, Wang AQ, Musson DG, Yang AY, Fisher AL (2003) A semiautomated 96-well protein precipitation method for the determination of montelukast in human plasma using high performance liquid chromatography/ fluorescence detection. J Pharm Biomed Anal 31: 647-654.

14. Sripalakit P, Kongthongc B, Saraphanchotiwitthayad A (2008) A simple bioanalytical assay for determination of montelukast in human plasma: Application to a pharmacokinetic study J Chromatogr B Analyt Technol Biomed Life Sci 869: 38-44

15. Foroutan, SM, Zarghi, A, Shafaati, A, Khoddam A (2005) A Rapid high performance liquid chromatographic determination of risperidone in human plasma. Irainian J Pharmaceut Res 1: 37-42

16. Zarghi A, Foroutan SM, Shafaati A, Khoddam A (2007) HPLC Determination of Letrozole in Plasma Using Fluorescence Detection: Application to Pharmacokinetic Studies. Chromatographia 66: 747-750

17. Amin RD, Cheng H, Rogers JD (1995) Determination of MK-0476 in human plasma by liquid chromatography. J Pharm Biomed Anal 13: 155-158.

18. Foroutan SM, Zarghi A, Shafaati A, Khoddam A (2003) Bioequivalence studies of two Iranian generic formulations of captopril in healthy volunteers. Arch Iranian Med 6: 44-52. 